\title{
An Optimization Model of EVs Charging and Discharging for Power System Demand Leveling
}

\author{
DU Guanhao ${ }^{1}$, CAO Wenping ${ }^{1}$, YANG Jin ${ }^{1}$ and ZHOU Bowen ${ }^{2}$ \\ 1. School of Engineer and Applied Science, Aston University, Birmingham B4 7ET, UK \\ 2. College of Information Science and Engineering, Northeastern University, Shenyang 110819, China
}

\begin{abstract}
This paper presents an advanced methodology for optimizing a UK network load demand with various uncertainties which are related to individual driving behaviours. Without the optimized regulation for traditional power system demand, EVs (electric vehicles) would have an adverse impact on the stability of power systems. This becomes more significant for large-scale EVs plugging into the power grid. Traditional optimized methodologies are effective only for EV charging. The proposed techniques improve the system flexibility and stability through an advanced optimization model and flexible bidirectional charging/discharging control. Three scenarios with different charging and discharging power levels and various penetration levels of EVs are discussed in detail in this paper. Simulation results demonstrate that bidirectional EV power flow control has vast potentials to improve the load demand profile, with increased proportion of EVs, and charging/discharging power levels.
\end{abstract}

Key words: Bidirectional EV charging, EVs, load demand, optimization model.

\section{Introduction}

With the increasing concerns over the depletion of fossil fuels and environmental sustainability, much attention has been attracted towards the development of EVs (electric vehicles) over the last 20 years. Since then, EVs are commonly regarded as one of the effective strategies to solve the environmental problems and also as an interface with utilizing renewable energy as both are distributed.

Owing to advanced development of EVs, numerous studies have been carried out to analyze their impacts on power systems. Several works have been focused on the different optimization models for power systems by utilizing EVs [1-9]. However, most other

Corresponding authors: DU Guanhao, Ph.D., student, research field: interaction of electric vehicles with grid. CAO Wenping, professor, chair in electrical power engineering, research fields: electric machine and drives, power electronic, power system analysis, electrified vehicles, wind power generation and measurement techniques. YANG Jin, Dr., lecturer, research fields: renewable power generation systems, active distribution systems and power system, and renewable power economics. ZHOU Bowen, Dr., lecturer, research fields: power systems analysis, electric vehicles. cases only consider coordinated charging or non-flexible charging methods [1-10]. For example, Masoum, A. S. et al. [1] consider about coordinating PEV (plug-in electric vehicle) charging by using a developed SLM (smart load management) control method for mitigating the increase in demand load at peak time. Similar studies also focus on uni-directional charging for PEVs [2-7], which analyze the impact on power distribution networks by using different proportions of electric vehicles, various seasons and different charging times. In Ref. [6], the power system has been studied at the valley time by charging EVs. The initial SOC (state of charge) is set between $10 \%$ and $20 \%$, and the final value is $95 \%$. However, it is not foresight option for future power systems to have a large scale of EVs which will be aggregated, since V2G (vehicle-to-grid) is potential support for power system leveling $[8,9]$. Moreover, the strategies of maximizing economic benefits by V2G technologies for supplier or consumer are also considered in some work $[1,10]$.

In this paper, a flexible and optimized model is developed for flattening the demand load in various 
scenarios over $24 \mathrm{~h}$ and one week ( $0.5 \mathrm{~h}$ interval). One typical charging profile of EV batteries is applied to charging models. The value of initial EV battery SOC is evolved from a PDF (probability density function) by using the travel distances data [11]. Different to existing studies, the probability of one-day trip is adopted in the optimization method for the precise charging/discharging power. By using this model, the EVs are more flexible than conventional schemes. They are available for EV charging or discharging at workplace or home at any time, rather than only charging from initial status.

This paper is divided into five sections as follows, Section 2 is the description of EV flexible charging networks with four parts. Section 3 proposes a new method to predict the energy capacity of EVs. Then one advanced optimization model is developed for flexible and bi-directional charging in Section 4. Finally, the simulation results are analyzed in Section 5 and summarized in Section 6.

\section{The Construction of EV Flexible Charging Networks}

(1) Load demand profile

From the flow chart in Fig. 1, the structure of EVs flexible charging networks is illustrated clearly. More specifically, from the input data, the profile of daily load demand is predicted as maximum demand value in winter season in 2020, according to the historical data from 2005-2015 [12], which can be seen from Fig. 2.

(2) The number of different EVs

Some researchers have forecasted the number of EVs in 2020. For instance, from Ref. [13], the number of EVs will be increased between 1.2-1.5 millions in $\mathrm{UK}$, hence, the value of pure BEVs (battery electric vehicles) and PHEVs (plug-in hybrid electric vehicles) is selected as 1.3 million for BEVs and 0.35 million for PHEVs respectively. The sum of EV number Ntotal is,

$$
\text { Ntotal }=N B+N P H
$$

from Eq. (1), $N B$ is number of $\mathrm{BEV}$, and $N P H$ is number of PHEV.

(3) Travel pattern and initial SOC status

The driving behavior can be divided into travel patterns and the initial SOC status, which are applied into the optimization model. The data of travel patterns can be acquired from the daily travel distance [11]. Moreover, the relationship between initial SOC and travel patterns is described as $\mathrm{U}_{\mathrm{SOC}}=1-\mathrm{d} / \mathrm{d}_{\mathrm{R}}$,

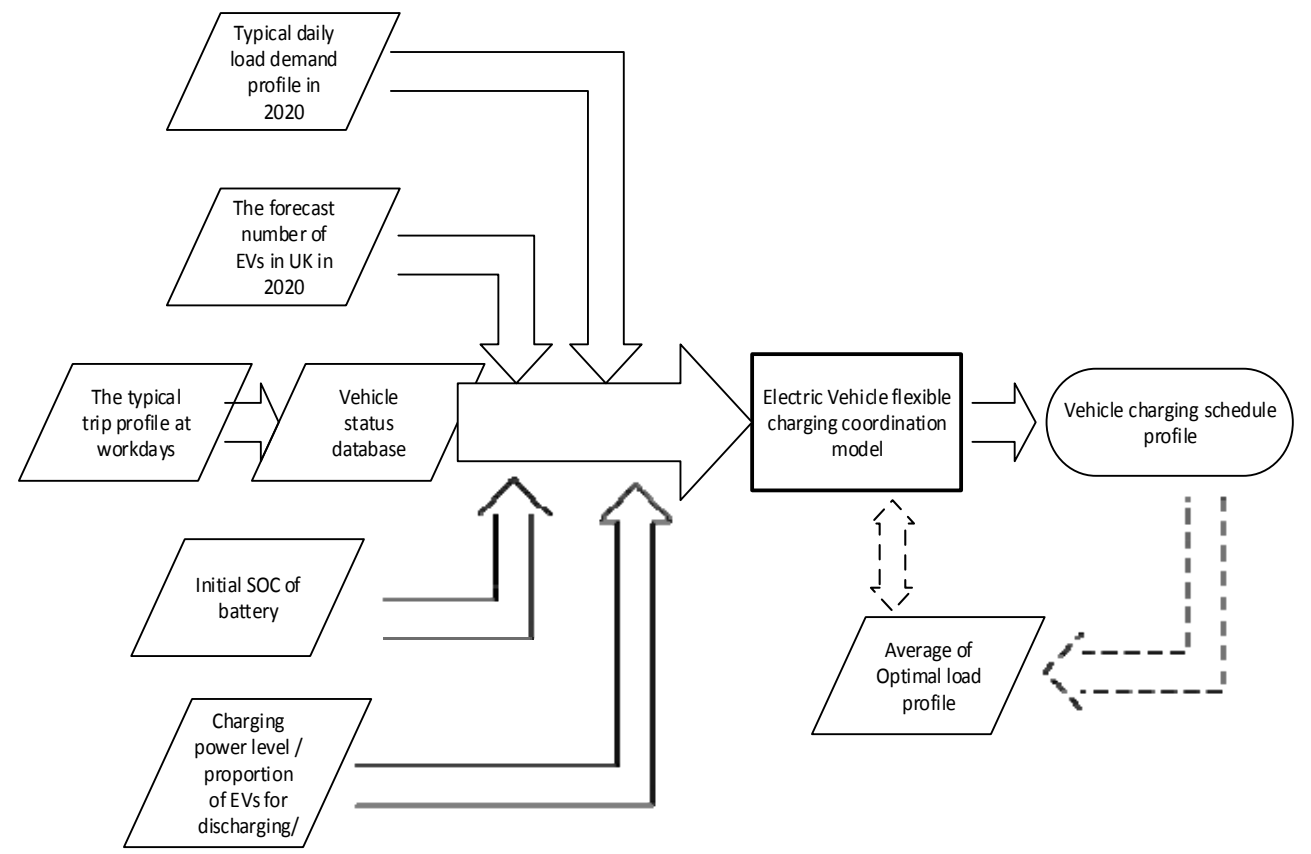

Fig. 1 The construction of EV flexible charging flow chart. 


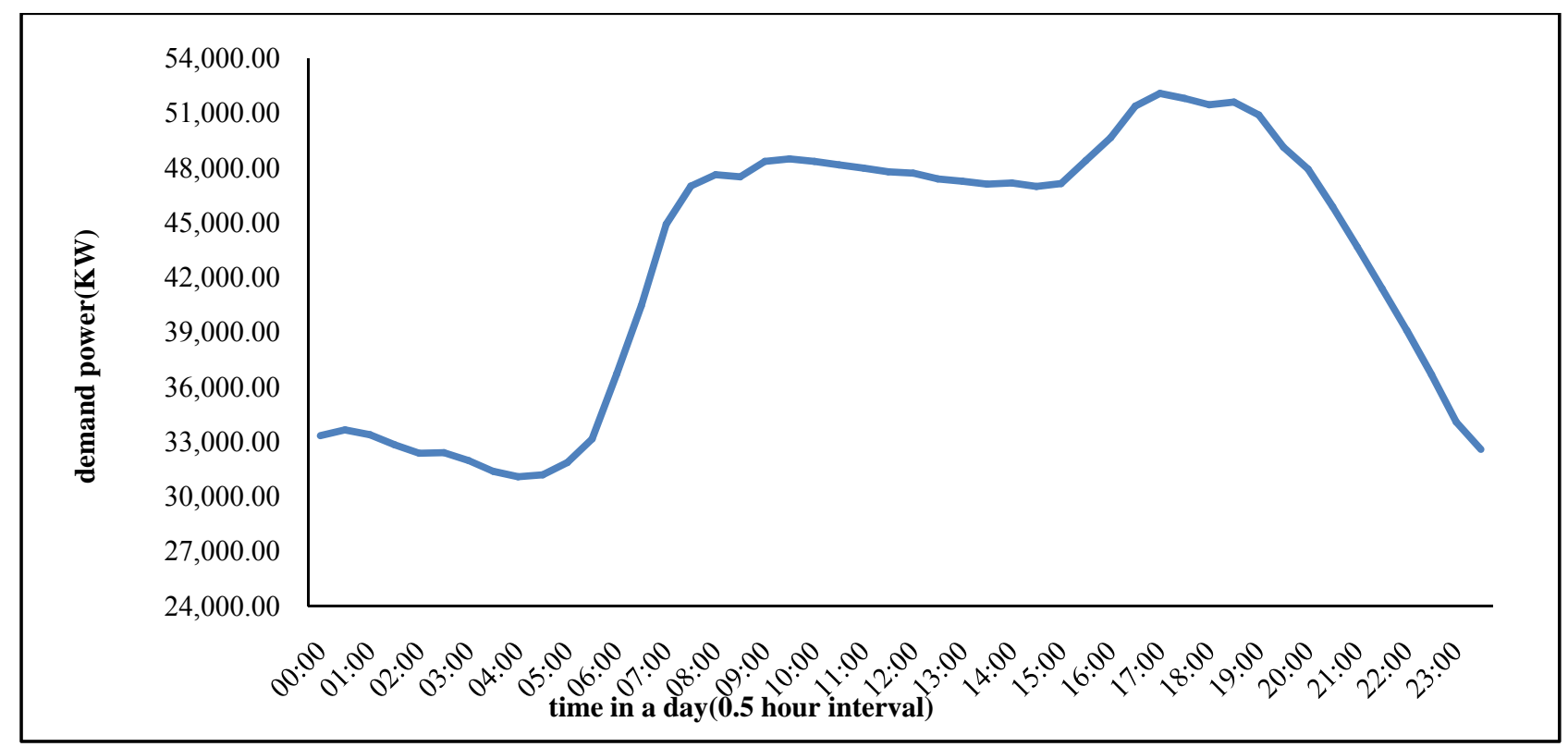

Fig. 2 The profile of load demand in a winter day.

where the PSOC is SOC of vehicle battery, $d$ is the daily travel distance and $d_{R}$ is assumed as the maximum distance for EVs. The SOC is estimated to decrease linearly with the distance rise. Therefore, the PDF of initial SOC after one-day trip is shown in Fig. 3.

$$
\begin{gathered}
h\left(U_{S O C} ; \mu, \sigma\right)=\frac{1}{d_{R}\left(1-U_{S O C}\right) \sqrt{2 \pi} \sigma} \times \\
e^{-\left[\ln \left(1-U_{\text {SOC }}\right)+\ln \left(\mathrm{d}_{\mathrm{R}}\right)-\mu\right]^{2} /\left(2 \sigma^{2}\right)^{2}}
\end{gathered}
$$

where, $\mu$ is the loge mean as well as $\sigma$ is the standard deviation of the corresponding daily travel distance probability density distribution, $0<\mathrm{U}_{\mathrm{SOC}}<1$. In this case, the $\mu$ and $\sigma$ are selected in normal day condition, hence, $\mu=3.20$ and $\sigma=0.6528$.

(4) The typical trip profile at workdays and weekends

It is clearly that the vehicles are not always connecting to the power networks and the status is continuously changing, which is unpredictable. Hence, the total energy of EVs for flexible charging or discharging is different during one day. By using the typical PDF of one-day trip which is shown on Fig. 4 [11], it is obvious to obtain PDF of vehicle status.

$$
\mathrm{G}_{\mathrm{VS}}=1-\mathrm{G}_{\mathrm{ODT}}
$$

where, the $\mathrm{G}_{\mathrm{ODT}}$ is the probability of vehicle travel,
$\mathrm{G}_{\mathrm{VS}}$ is the probability of vehicle online respect to power system.

Compare with the part (3), the probability of vehicle trip is also one of the important elements, which will be talked about in detail in the followed chapter.

\section{Energy Capacity of EVs for Power System}

(1) Characteristics of EVs battery charging and discharging

Normally, for the power system networks, EVs usually act as a load with typical characteristic of battery charging. However, in this paper, the EVs are also seen as energy supplier to support the power system demand. For the lithium-ion batteries EVs, the IEC 61581-1 standard is adopted and it illustrates four charging modes which can be seen from Table 1 [14].

For the flexible charging, it is assumed that the EVs are available charging at home or public charging station like at office. Consider about the charging process, a typical battery charging level can be mathematically expressed as below,

$$
P_{C}(t)=\left\{\begin{array}{c}
P_{R}, 0<t \leq t_{1} \\
P_{R} \frac{\left(t_{2}-t\right)}{\left(t_{2}-t_{1}\right)}, t_{1}<t \leq t_{2}
\end{array}\right.
$$




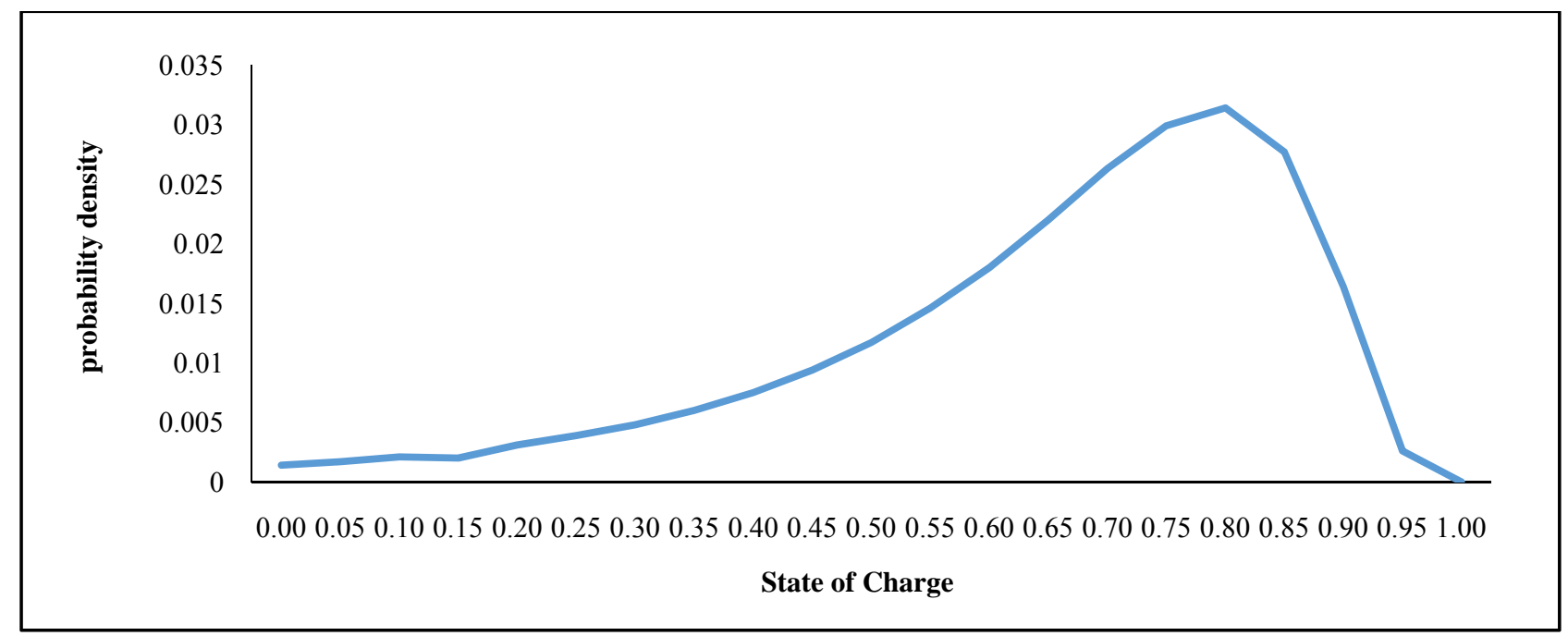

Fig. 3 Probability density of battery SOC after one-day travel.

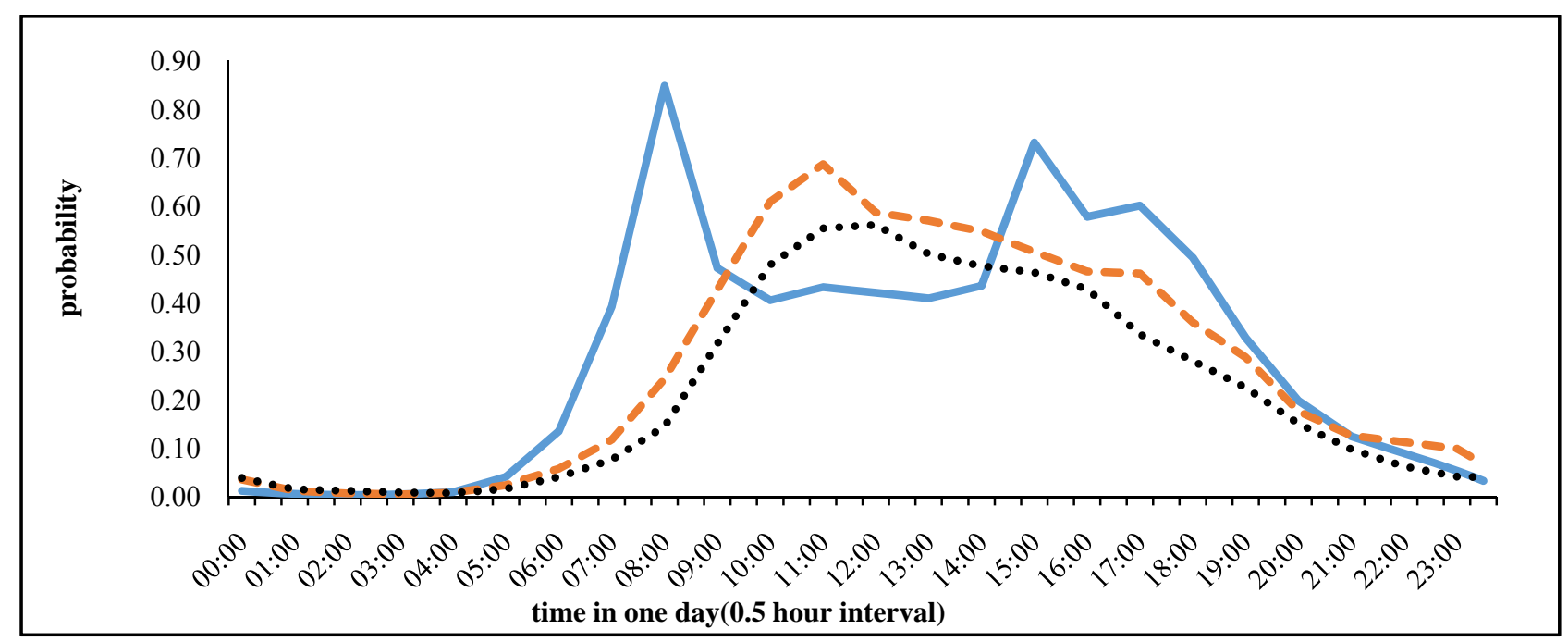

Fig. 4 Probability density of trip on workdays and weekends (solid line: on workdays, point dash line: on Saturday, dash line: on Sunday).

Table 1 Standard charging modes in IEC 61851-1 [14].

\begin{tabular}{llll}
\hline Mode & Phase & Maximum current & Maximum voltage \\
\hline \multirow{2}{*}{1 (AC) } & 1 & $16 \mathrm{~A}$ & $250 \mathrm{~V}$ \\
& 3 & $16 \mathrm{~A}$ & $480 \mathrm{~V}$ \\
$2(\mathrm{AC})$ & 1 & $32 \mathrm{~A}$ & $250 \mathrm{~V}$ \\
& 3 & $32 \mathrm{~A}$ & $480 \mathrm{~V}$ \\
$3(\mathrm{AC})$ & 1 & $32 \mathrm{~A}$ & $250 \mathrm{~V}$ \\
& 3 & $250 \mathrm{~A}$ & $690 \mathrm{~V}$ \\
$4(\mathrm{DC})$ & 1 & $400 \mathrm{~A}$ & $600 \mathrm{~V}$ \\
\hline
\end{tabular}

where, $P_{C}(t)$ is the charge rate of battery at time t, $P_{R}$ is rated charging power and it is defined by the different charging mode. In addition, $t_{1}$ and $t_{2}$ are the time which determines the different progress during the battery charging.

Moreover, according to characteristic of battery [15], discharging process is similar with the charging process, with the reversed direction. In consequence, depends on the charging power and battery characteristics, the discharging power level is expressed,

$$
P_{R D}(t) \leq \min \left\{P_{R}, P_{B D}\right\}
$$

where, $P_{R D}(t)$ is rate discharging power at time t, $P_{B D}$ is rate discharging power of battery.

(2) Discrete calculation for $\mathrm{EV}$ charging/discharging power 
Since the load demand profile is in $0.5 \mathrm{~h}$ interval, the continuous battery charging and discharging power will be divided into discrete 48 time intervals for steady-state analysis. On the basic of Eq. (4), the discrete bidirectional charging power $P_{j}$ for the $j$ th period is,

For charging:

$$
P_{j}=\int_{(j-1) T}^{j T} P_{c}(t) / T d t, 1 \leq j \leq T_{c}, T_{r}=24 / N_{d}
$$

For discharging:

$P_{j}=\int_{(j-1) T}^{j T} P_{d c}(t) / T d t, 1 \leq j \leq T_{d c}, T_{r}=24 / N_{d}(7)$

where, $T_{c}$ is the number of periods for charging to full SOC and $T_{d c}$ is the number of periods for discharging to battery empty. In addition, $T_{c}$ and $T_{d c}$ are rounded up to the closest time interval for bidirectional charging, since by utilizing modes 3 and 4, the period time is $0.75 \mathrm{~h} . N_{d}$ is the number of equal time periods during one day which is defined by the load demand profile time intervals. Here $N_{d}=48$ and $T_{r}=0.5 \mathrm{~h}$.

(3) Capacity model of EV flexible bidirectional charging

For the flexible EV connecting to power system networks, the EVs are frequently controlled in every interval. According to Eqs. (6) and (7), assuming the discrete SOC $U_{S O C c j}$ and $U_{S O C d j}$ before charging and discharging start in each time interval respectively, the probability of a battery starting charge or discharge at time $g$ with power level $P_{c j}$ and $P_{d c j}$ at later time $h$ is shown below,

$\left\{\begin{array}{c}\varphi\left(P_{c j}, h\right)=\sum_{g=1}^{h} f(g) h\left(U_{\text {SOCc } j}-\sum_{i=1}^{m} U_{\text {SOCci }}\right) \\ N_{c} \leq h \leq N_{d}, m=h-g<j ; \text { for charging } \\ \varphi\left(P_{d c j}, h\right)=\sum_{g=1}^{h} q(g) h\left(U_{\text {SOCd } j}-\sum_{i=1}^{m} U_{\text {SOCdi }}\right) \\ N_{c} \leq h \leq N_{d}, m=h-g<j ; \text { for discharging }\end{array}\right.$

where, $f(g)$ is the probability of a charging process beginning at $g$ and $q(g)$ is the probability of a discharging process beginning at $g$. Moreover, $h\left(U_{S O C C j}-\sum_{i=1}^{m} U_{S O C C i}\right)$ is the probability of an initial battery SOC from which the EV charging at power level $P_{c j}$ and the probability of an initial battery SOC from which the EV discharging at power level $P_{d c j}$ is $h\left(U_{S O C d j}-\sum_{i=1}^{m} U_{S O C d i}\right)$.

The total energy of plenty of EVs is the sum of charging and discharging demand of individual EVs. Assuming $n_{a}$ and $n_{b}$ are the number of batteries for charging and for discharging separately. $n_{a}$ is the ith EV and $i=1,2,3, \ldots, n$. Thus the demand energy of bidirectional charging can be expressed as,

$$
\left\{\begin{array}{c}
P_{E V 1}=\sum_{i=1}^{n_{a}} \sum_{j=1}^{N_{d}} P_{j} \times \varphi\left(P_{c j}, h\right) \times\left(1-\mathrm{G}_{\mathrm{ODT}}\right) \\
n_{a} \leq N_{B} ; P_{\text {load }} \leq \bar{P}_{\text {mean }} \\
P_{E V 2}=\sum_{i=1}^{n_{b}} \sum_{j=1}^{N_{d}} P_{j} \times \varphi\left(P_{d c j}, h\right) \times\left(1-\mathrm{G}_{\mathrm{ODT}}\right) \\
n_{b} \leq N_{B} ; P_{\text {load }} \geq \bar{P}_{\text {mean }}
\end{array}\right.
$$

where, $P_{E V 1}$ is the charging demand of $n_{a}$ EVs at time $h$, and $P_{E V 2}$ is the discharging power of $n_{b}$ EVs at instant time $h . \bar{P}_{\text {mean }}$ is the average demand power. Hence, the total energy of $n_{c}$ EVs for bidirectional charging is given as:

$$
P_{E V}=P_{E V 1}-P_{E V 2} ; n_{c}=n_{a}+n_{b}
$$

\section{Optimization Model}

From power networks demand in Fig. 2, it has apparent periodic variations between peak and valley magnitudes over one day. Moreover, in the period between 8:00 am and 20:00 pm, the load demand encounters peak time dramatically, since a large number of non-EV loads are connecting to power grid. However, the load demands will drop sharply from 20:00 pm to next day 8:00 am, which has enormous impact on power generations. By utilizing EVs together through optimization model can release the pressure from consumer load to power system. In this section, the flat and stable power system profile is taken as first target for the optimization of grid demand.

In this paper, the power system demand $P_{\text {total }}$ can be segmented as two parts which is expressed below,

$$
P_{\text {total }}(h)=P_{E V}(h)+P_{L}(h)
$$

where, $P_{E V}(h)$ is the total energy of variable EV at time $h$, and $P_{L}(h)$ is the sum of demand energy without $\mathrm{EV}$ at time $h$. 
One significant problem of optimization model is minimizing the variations from original power system demand $P_{\text {total }}$ by applying its mean value, which is expressed as,

$$
\begin{gathered}
\min Z\left(P_{\text {total }}\right)=1 / N_{d} \sum_{h=1}^{N_{d}}\left(P_{\text {total }}(h)-\bar{P}_{\text {mean }}\right)^{2} \\
=1 / N_{d} \sum_{h=1}^{N_{d}}\left(P_{\text {total }}(h)^{2}-2 P_{\text {total }}(h) \bar{P}_{\text {mean }}+\bar{P}_{\text {mean }}{ }^{2}\right) \\
=1 / N_{d} \sum_{h=1}^{N_{d}} P_{\text {total }}(h)^{2}-2 \bar{P}_{\text {mean }} / N_{d} \sum_{h=1}^{N_{d}} P_{\text {total }}(h)+\bar{P}_{\text {mean }}{ }^{2} \\
=1 / N_{d} \sum_{h=1}^{N_{d}} P_{\text {total }}(h)^{2}-\bar{P}_{\text {mean }}^{2}
\end{gathered}
$$

where $\bar{P}_{\text {mean }}$ is the average demand power over one day. Since the power system profile is constant, with a certain number of EVs is defined, the sum of system energy demand would be constant. In addition, the average system power is invariant which equals to the total power system demand during one day. It is obvious that there is nearly no effect on the result of the minimization, thus the second part in Eq. (12) can be ignored.

Substituting Eqs. (9)-(12), the minimization problem would be reformulated and expressed as below,

$$
\begin{gathered}
\min Z=\sum_{h=1}^{N_{d}}\left(P_{E V}(h)+P_{L}(h)\right)^{2}=\sum_{h=1}^{N_{d}}\left(P_{E V 1}(h)-P_{E V 2}(h)+P_{L}(h)\right)^{2} \\
=\sum_{h=1}^{N_{d}}\left(n_{a} \sum_{j=1}^{N_{d}} P_{j} \times \varphi\left(P_{c j}, h\right) \times\left(1-\mathrm{G}_{\mathrm{ODT}}\right)-n_{b} \sum_{j=1}^{N_{d}} P_{j} \times \varphi\left(P_{d c j}, h\right) \times\left(1-\mathrm{G}_{\mathrm{ODT}}\right)+P_{L}(h)\right)^{2} \\
\left\{\begin{array}{c}
\varphi\left(P_{c j}, h\right)=\sum_{g=1}^{h} f(g) h\left(U_{\text {SOCcj }}-\sum_{i=1}^{m} U_{\text {SOCci }}\right) \\
N_{c} \leq h \leq N_{d}, m=h-g<j ; \\
\varphi\left(P_{d c j}, h\right)=\sum_{g=1}^{h} q(g) h\left(U_{\text {SOCdj }}-\sum_{i=1}^{m} U_{\text {SOCdi }}\right) \\
N_{c} \leq h \leq N_{d}, m=h-g<j \\
\text { Subject to }\left\{\begin{array}{c}
\sum f(h)+\sum q(h)=1 \\
f(h) \geq 0, q(h) \geq 0, \forall t \in\left[1, N_{d}\right]
\end{array}\right.
\end{array}\right.
\end{gathered}
$$

where, $\mathrm{Z}$ is the objective function to minimize the optimization problem. In addition, $f(h)$ and $q(h)$ are the decision variables which are the proportion of EVs that begin charging and discharging at time $h$. This optimization problem from Eq. (13) is essentially a SQP (sequential quadratic programming) with bound constraints and linear equation [16, 17], which can be processed in MATLAB [18].

\section{Case Study for Levelling Load}

In this case, a UK 2020 winter national demand has been applied through MATLAB through optimization model. It is assumed that the maximum travel distance is approximately 80 miles for average EVs. Due to a 
large number of vehicles would be used by their owners for working, shopping, education and vacations, it is essential to take probability of vehicle vacancy $\mathrm{G}_{\mathrm{ODT}}$ over $24 \mathrm{~h}$ (48 intervals). And it not only considers about charging or discharging at home, but also taking charging or discharging at car park during workplace.

(1) Parameters

In this section, according to bidirectional charging power levels, weather conditions, intervals times during $24 \mathrm{~h}$ and the vehicle batteries, all parameters are listed in Table 2.

Table 2 List of parameters for EV bidirectional charging.

\begin{tabular}{llll}
\hline Symbol & Value & Symbol & Value \\
\hline$N B$ & $1.3 \mathrm{million}$ & $N P H$ & $0.35 \mathrm{million}$ \\
$E_{B 1}$ & $25 \mathrm{kWh}$ & $E_{B 2}$ & $5 \mathrm{kWh}$ \\
$T_{\text {istart }}$ & 0 & $T_{\text {iend }}$ & 47 \\
$N_{d}$ & 48 & $T_{a}$ & 24 \\
$\mu$ & 3.20 & $\sigma$ & 0.6528 \\
$P_{R 1}$ & $3.5 \mathrm{~kW}$ & $P_{R D 1}$ & $3.5 \mathrm{~kW}$ \\
$P_{R 2}$ & $6.6 \mathrm{~kW}$ & $P_{R D 2}$ & $6.6 \mathrm{~kW}$ \\
$P_{R 3}$ & $40 \mathrm{~kW}$ & $P_{R D 3}$ & $40 \mathrm{~kW}$ \\
\hline
\end{tabular}

where, $E_{B 1}$ and $E_{B 2}$ are the capacity of BEV (battery electric vehicle) and PHEV (plug-in hybrid electric vehicle) respectively. $T_{\text {istart }}$ is the first interval over whole experimental period, and $T_{i e n d}$ is the last interval during whole period. Furthermore, the parameters of different bidirectional charging and discharging levels regarding to BEV and PHEV are discussed in Tables 3 and 4 separately.

Table 3 List of parameters for BEVs with different charging and discharging levels.

\begin{tabular}{llll}
\hline Symbol & Mode 1 & Mode 2 & Mode 3 \\
\hline$P_{R}$ & $3.5 \mathrm{~kW}$ & $6.6 \mathrm{~kW}$ & $40 \mathrm{~kW}$ \\
$P_{R D}$ & $3.5 \mathrm{~kW}$ & $6.6 \mathrm{~kW}$ & $40 \mathrm{~kW}$ \\
$t_{1}$ & $6.3 \mathrm{~h}$ & $3.6 \mathrm{~h}$ & $0.5 \mathrm{~h}$ \\
$t_{2}$ & $8 \mathrm{~h}$ & $4 \mathrm{~h}$ & $0.7 \mathrm{~h}$ \\
$U_{\text {Socmin }}$ & 0.5 & 0.5 & 0.5 \\
\hline
\end{tabular}

Table 4 List of parameters for PHEVs with various charging and discharging levels.

\begin{tabular}{llll}
\hline Symbol & Mode 1 & Mode 2 & Mode 3 \\
\hline$P_{R}$ & $3.5 \mathrm{~kW}$ & $6.6 \mathrm{~kW}$ & $40 \mathrm{~kW}$ \\
$P_{R D}$ & $3.5 \mathrm{~kW}$ & $6.6 \mathrm{~kW}$ & $40 \mathrm{~kW}$ \\
$t_{1}$ & $1.26 \mathrm{~h}$ & $0.72 \mathrm{~h}$ & $0.1 \mathrm{~h}$ \\
$t_{2}$ & $1.6 \mathrm{~h}$ & $0.8 \mathrm{~h}$ & $0.15 \mathrm{~h}$ \\
$U_{\text {socmin }}$ & 0.5 & 0.5 & 0.5 \\
\hline
\end{tabular}

(2) Simulation results

Base on all above sections, in this simulation, it has three scenarios which will be investigated later.

(a) All EVs are only adopted for charging at home or workplace by different power levels (Modes1-3).

(b) All EVs are applied for charging and discharging according to optimization model at home or workplace by different power levels (Modes1-3).

(c) Various proportions of EVs are utilized for charging/discharging at $3.5 \mathrm{~kW}$ power level in winter and summer.

(d) All EVs are operated in charging/discharging on weekdays, Saturdays and Sundays at $3.5 \mathrm{~kW}$ power level.

According to all these scenarios, the power system demand is monitored and investigated in each $0.5 \mathrm{~h}$ over $24 \mathrm{~h}$. With the help optimization for boundary constrains, the mean power system demand is not simple average power system demand. It is related with the value of EVs supply energy. Although there are different percentages of EVs being applied in scenarios, the total number of EVs is constant value.

More specifically, according to the first scenario, whole EVs can be seen as additional load for make up the valley of total power system. From Fig. 5, various power levels are utilized, such as $3.5 \mathrm{KW}, 6.6 \mathrm{~kW}$ and $40 \mathrm{~kW}$ for levelling the load demand. In addition, it is obvious that with the increase of the charging power from $3.5 \mathrm{~kW}$ to $40 \mathrm{~kW}$, the tendency of optimized power system demand is approaching to the mean power system demand. Moreover, between 21:00 pm and 6:00 am, there would have much energy flowing from batteries to power grid for offsetting the gap. Nevertheless, during time period excepting the time which was mentioned above, it has only a little power exchanging between EVs and power system. Since non-EVs load demand requires much more power from power grid as well as the value of load demand is exceeding the average power system demand, there is nearly no change compare with original gross load demand. In addition, with the probability of vehicle 


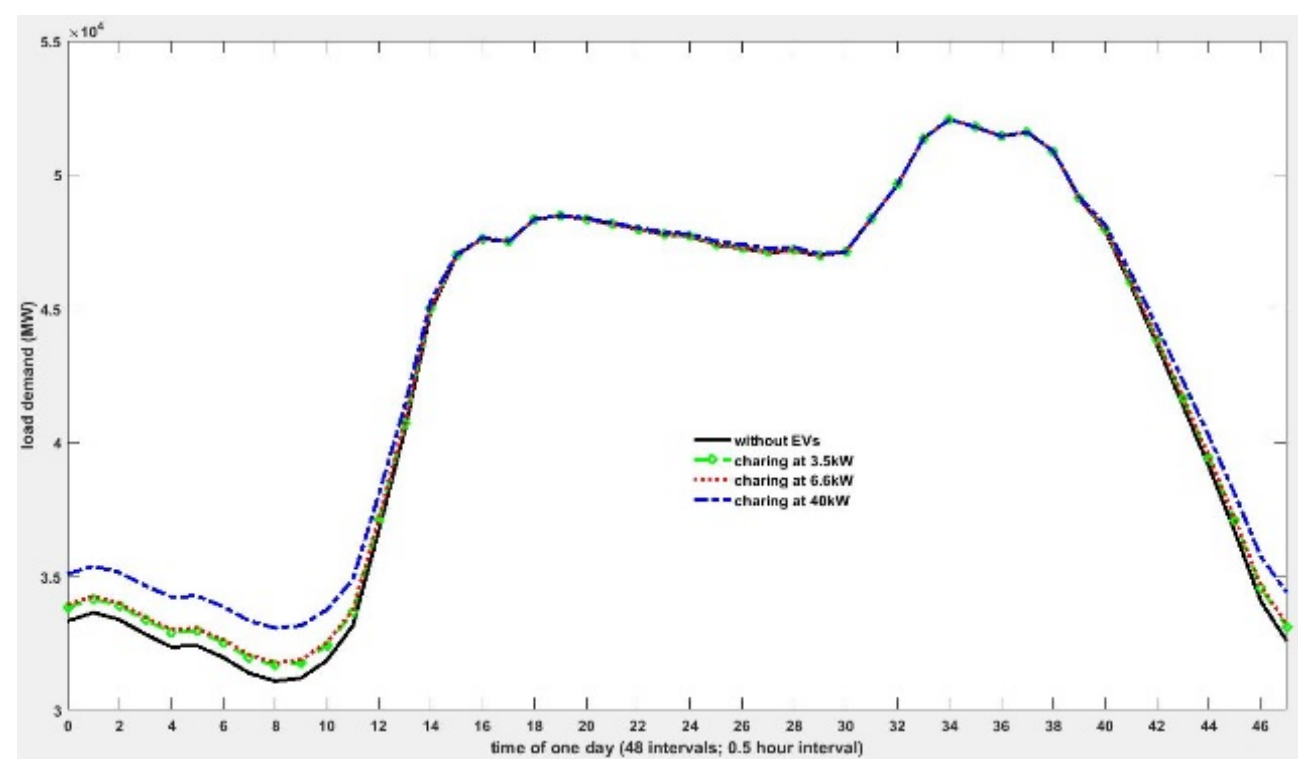

Fig. 5 Optimal load profile for only charging in different power level.

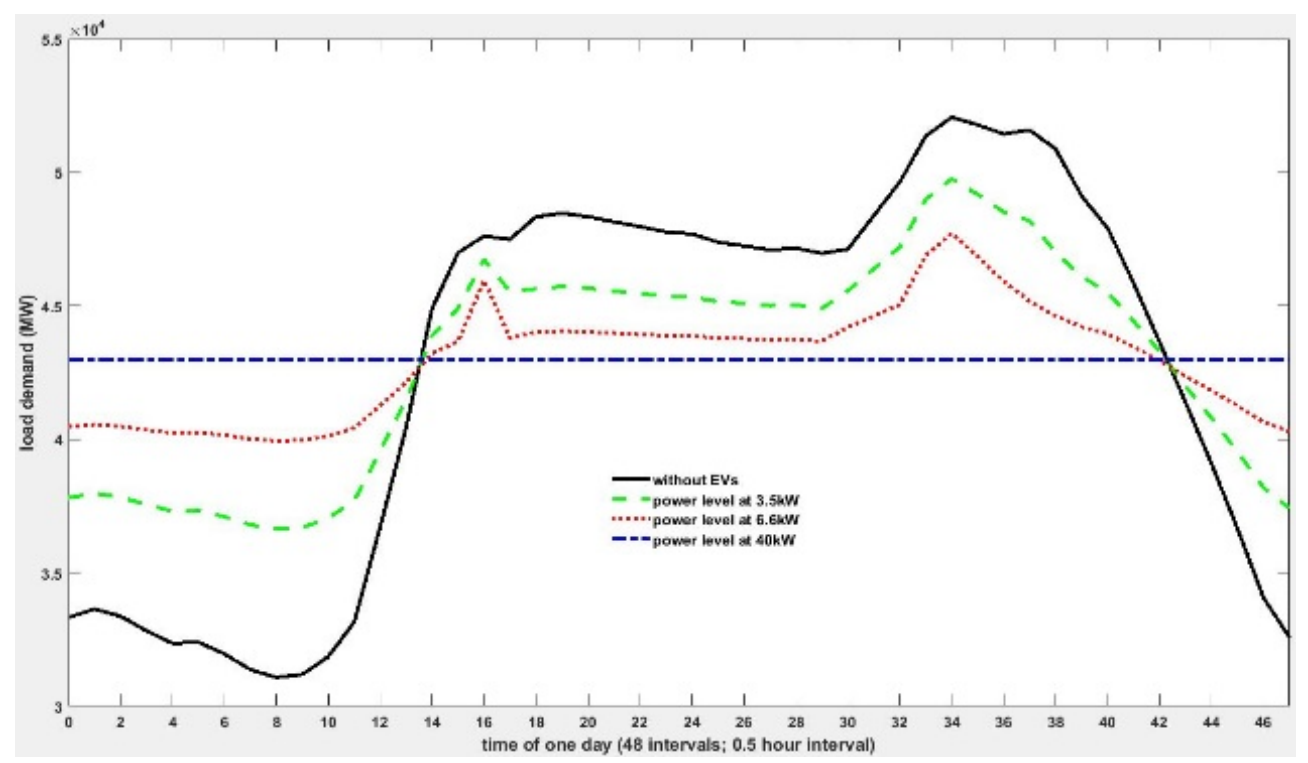

Fig. 6 Optimal load profile for flexible charging in different power level.

online is in low proportion, the energy from batteries which can be used is also under poor condition.

Compared with scenario 1 , which is only charging from power systems, the scenarios 2 has more benefits to power grid. Through the optimization described above, all cases (green, red and blue profiles) in scenario 2 have been flattening obviously in different levels from Fig. 6. It is not only charging as a normal load during 7:00 am and 21:00 pm, but discharging as supply generations for power grid during the rest time from Fig. 7. More precisely, in green line (charging and discharging at $3.5 \mathrm{~kW}$ ) during $24 \mathrm{~h}$, it is apparently that the optimized power system demand profile is drawn near to the optimal tendency. By applying higher power level $6.6 \mathrm{~kW}$, it has similar trend with the green line $(3.5 \mathrm{~kW})$ and it is much closer to the mean load demand. In addition, according to the probability of vehicle travel from Fig. 4, it is clear to discover that some fluctuations have occurred during the periods between 7:00 am and 8:30 am, and 16:30 pm and 18:30 pm respectively. However, since the power level in Mode 3 (at $40 \mathrm{~kW}$ ) is much higher than, 


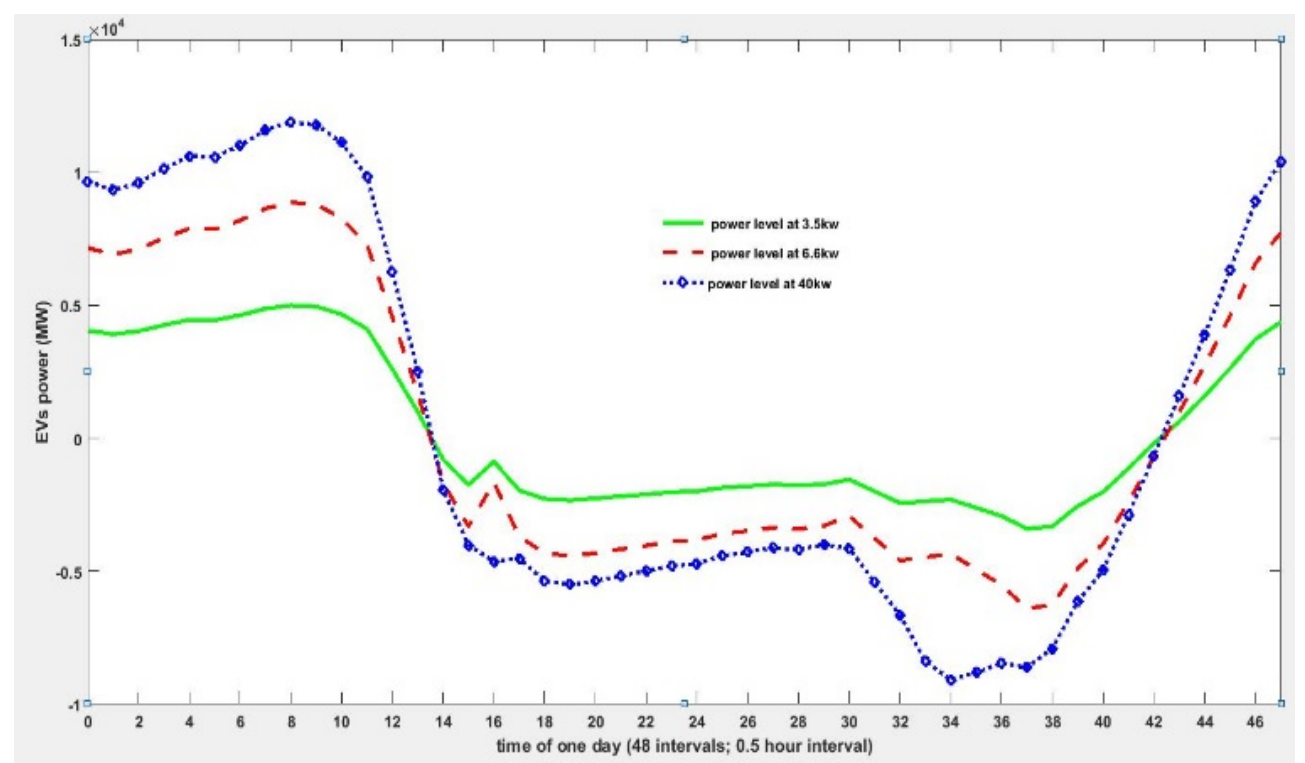

Fig. 7 EV power profile for flexible charging in different power level.

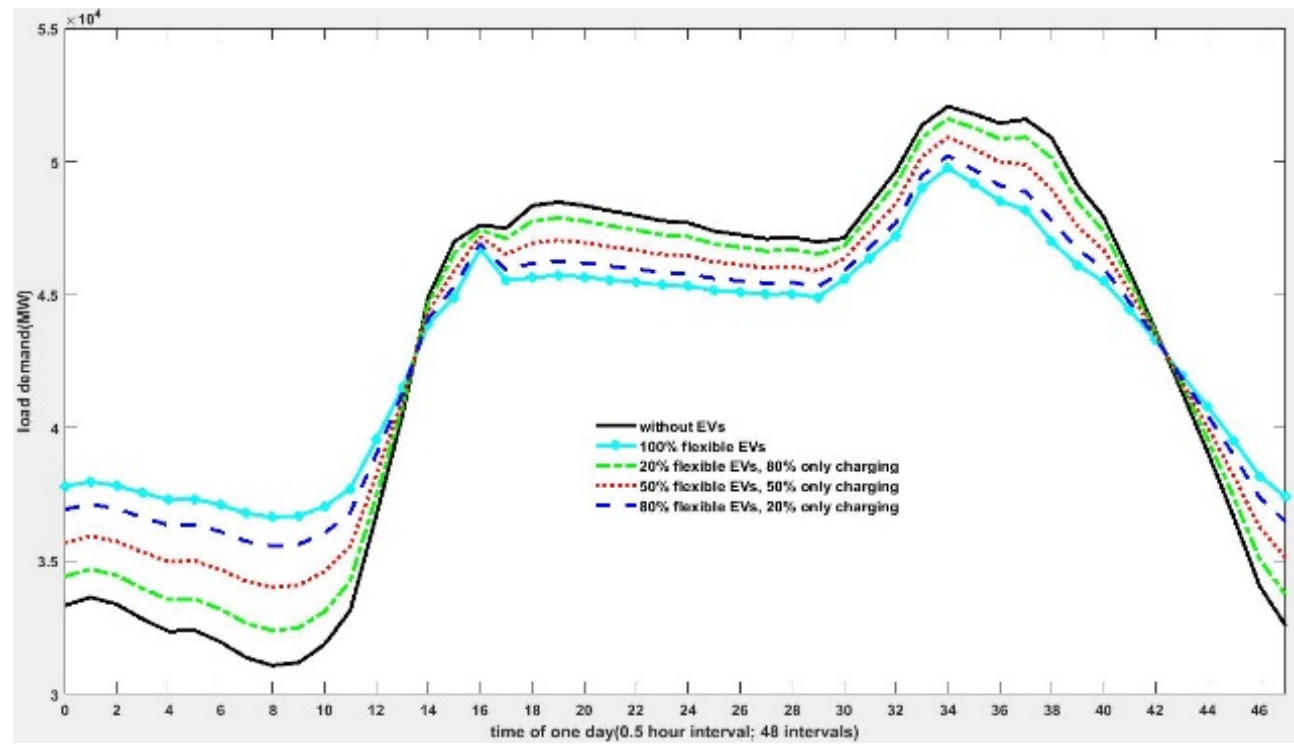

Fig. 8 Optimal load profile for flexible charging in different EV proportion with $3.5 \mathrm{~kW}$ power level in winter.

Modes 1 and 2, the optimized power system demand in blue line is under the idealized situation.

In third scenario, the all types of optimized load demand are related with different proportions of available EVs for flexible bidirectional charging. From Figs. 8 and 9, with the raise of percentage of available EVs for various cases $(100 \% \mathrm{EVs}$ in light blue, $80 \%$ EVs in dark blue, 50\% EVs in red and 20\% EVs in green for flexible bidirectional charging), the optimized profile would approach closer to the optimal demand load. Moreover, based on probability of vehicle travel from Fig. 4, the fluctuations happen within 48 intervals $(1$ interval $=0.5 \mathrm{~h})$. Compare with the results in winter, the optimized profile would also get closer to the optimal demand load, with increasing proportion of available EVs for flexible charging and discharging in summer period, which can been seen in Fig. 10.

In the last scenario, all EVs are applied for charging and discharging with $3.5 \mathrm{~kW}$ power level on different days (Weekdays, Saturdays and Sundays). Compare with other scenarios, with various probabilities of 


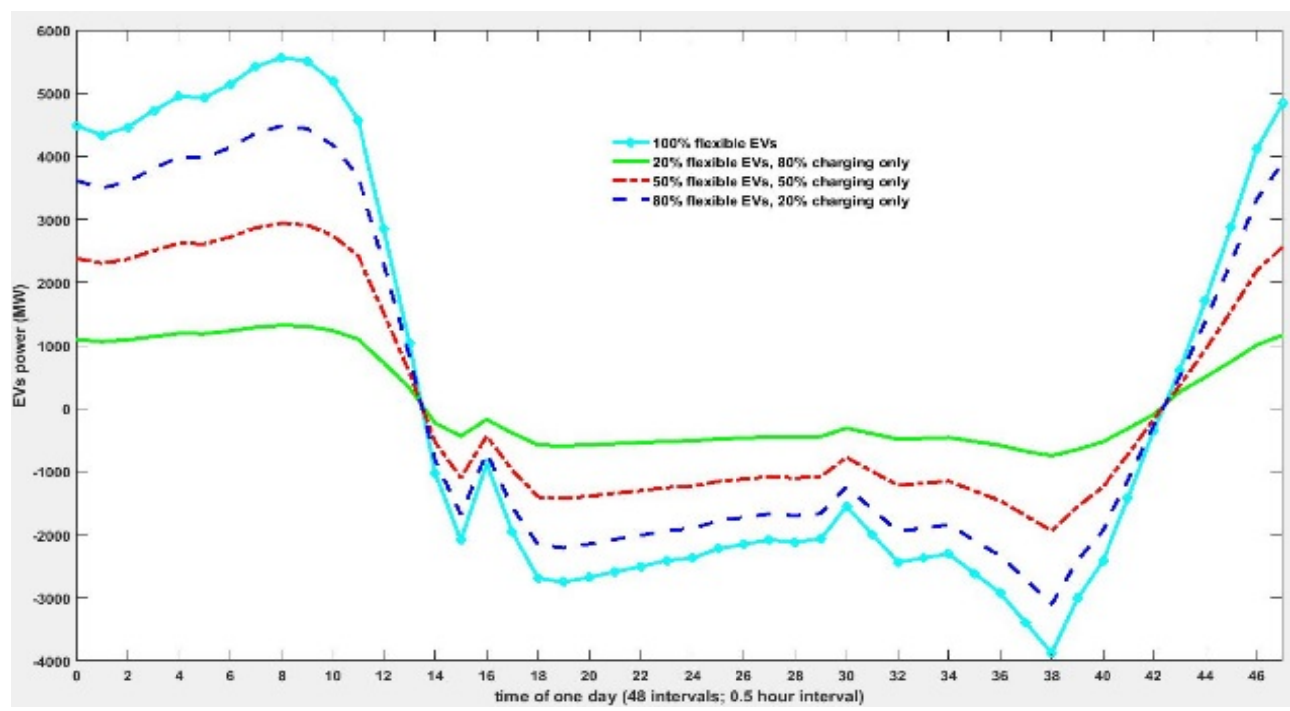

Fig. 9 EV power profile for flexible charging in different EV proportion.

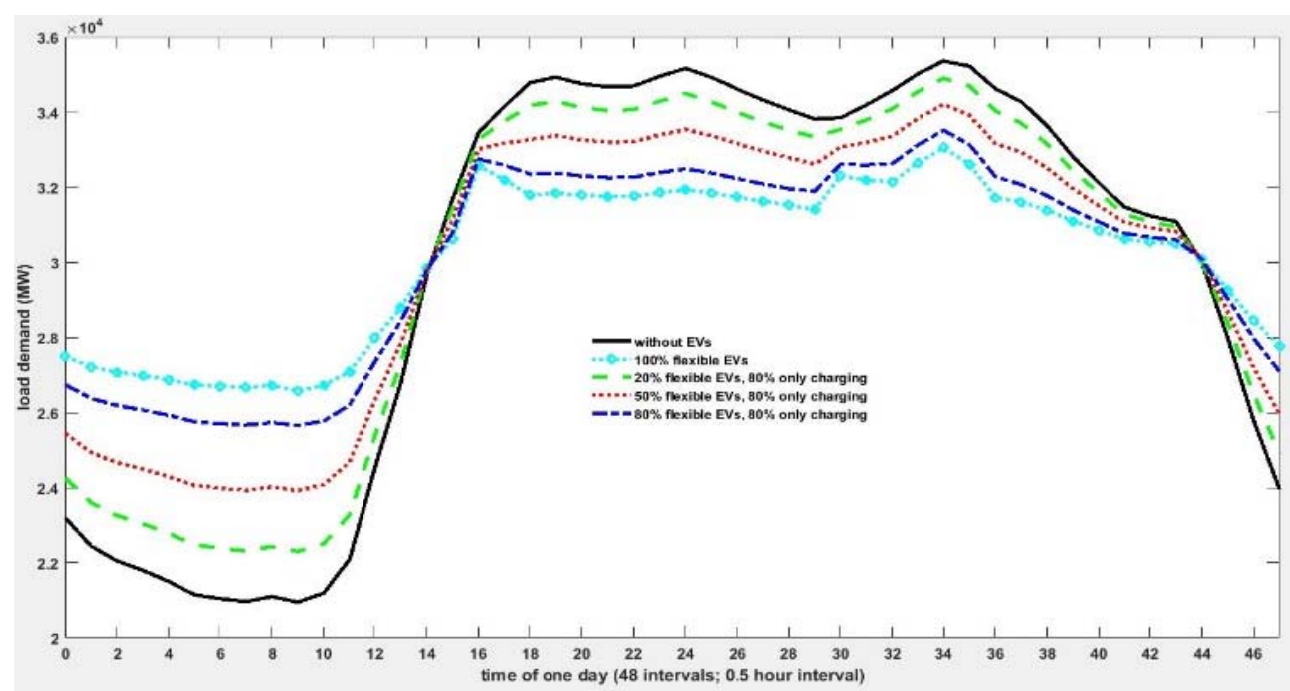

Fig. 10 Optimal load profile for flexible charging in different EV proportion with $3.5 \mathrm{~kW}$ power level in summer.

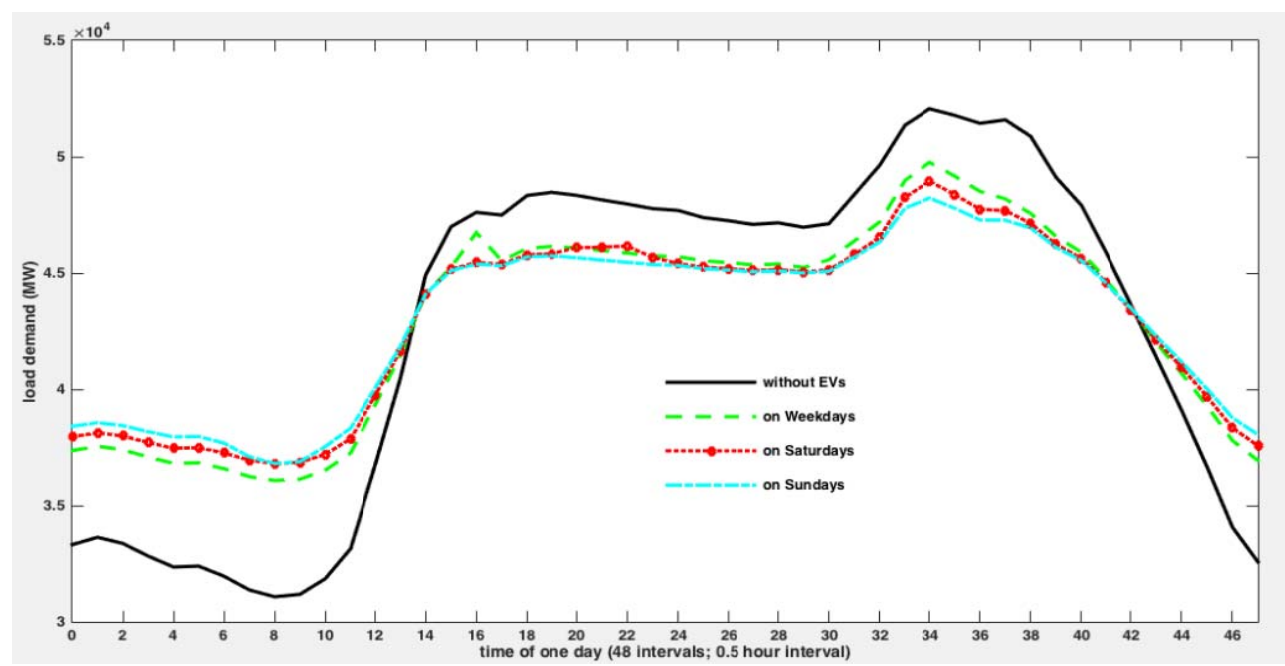

Fig. 11 Load demand profile of charging/discharging with different probability of vehicle travelling. 


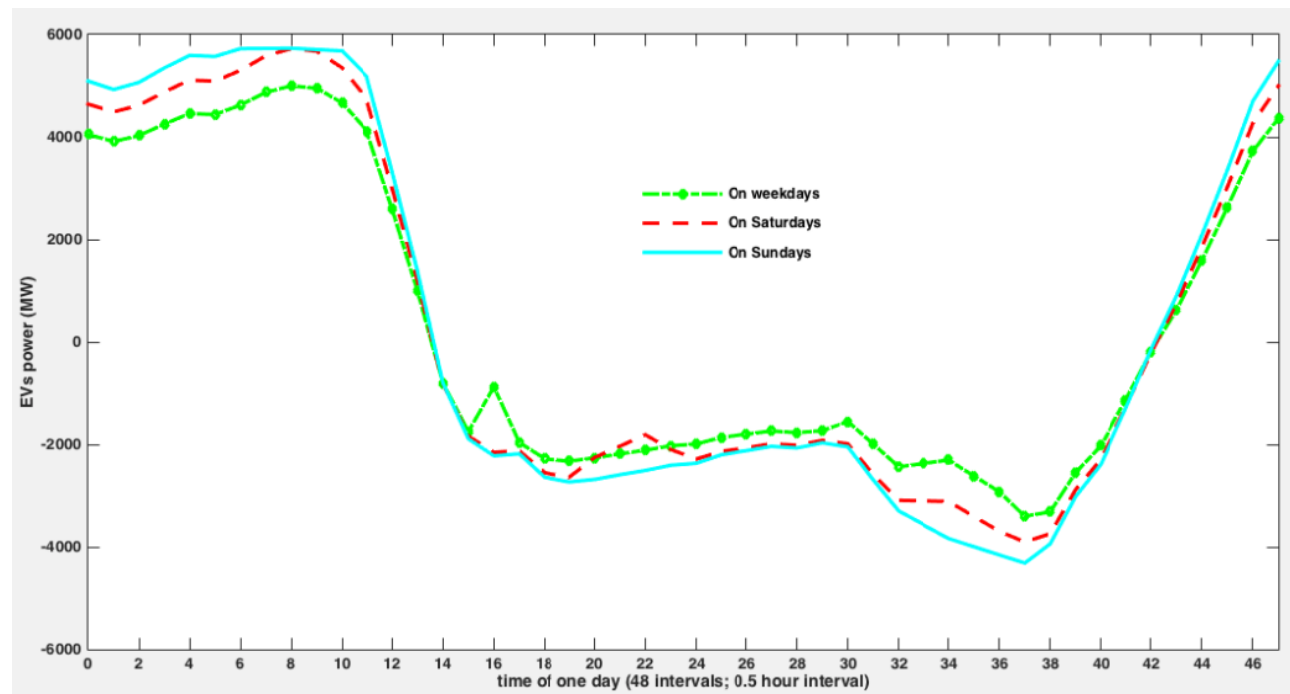

Fig. 12 EVs power profile of charging/discharging with different probability of vehicle travelling.

online vehicle GVS, the results of optimal load profile would be different by connecting different number of EVs online at the same time practically, which can been seen in Figs. 11 and 12. According to Fig. 4 probability of trip density on weekdays, Saturdays and Sundays, it is apparent to find some fluctuations during the peak time on workdays, comparing with the profiles on weekends.

\section{Conclusions}

With continued development of smart grid technologies and communication interaction, EVs could be utilized through aggregators or as individuals for smart charging from power system to level the valley gap, as well as through energy storage to supply weak power networks. This paper has described a construction of EV flexible charging networks. More specifically, it takes several elements into account, such as UK's national load demand profiles, the total number of BEVs and PHEVs, the initial SOC of EV batteries based on travel distance and probability of vehicle travel. In addition, the operating power levels and various proportions of available EVs would be significant input parameters for optimized charging. A forecasting model of EV energy capacity is extensively discussed. Furthermore, typical charging and discharging characteristic of EV batteries, and stochastic start and end time of batteries charging and discharging process is formulated for predicting available EV capacity. The most vital part for flexible charging is an advanced optimization model developed for levelling power system demand, and thus it can improve power grid stability and relax the pressure from national generation. It is obvious that without advanced optimized regulation, the total EVs would bring enormous impact on the power system. By using the optimization model, four scenarios are discussed and demonstrated. It illustrates the fluctuations in original power system demand would decrease by applying EVs for flexible charging and discharging. In addition, the tendency of load demand profile would approach gradually to mean power system demand when increasing the charging and discharging power level from $3.5 \mathrm{~kW}$ to $40 \mathrm{~kW}$. The results of load demand profile would be better with enhanced penetration levels of EVs at $20 \%, 50 \%$, $80 \%$ and $100 \%$ respectively. However, the probability of vehicle travel is also a significant element for the restriction of EV available capacity. Due to the probability of vehicle online respect to power system according to different days, which is reformulated by probability of vehicle travel, is used in optimization method, the optimized profiles of load demand would yield a better and more practical result. 
The optimization methodology proposed in this paper is suitable for optimizing power system operation in different circumstances. For instance, it can be applied in industrial, commercial and residential load demand which the detailed information of demand profiles is known. The further steps for this research will enhance and solidify this model for long time periods and residential loads. In addition, the distributed energy and different aging conditions of batteries will be taken into account. Several cases such as minimization of power losses, voltage and frequency variations and harmonics in power systems will be discussed and simulated in the future work.

\section{References}

[1] Masoum, A. S., Deilami, S., Moses, P. S., Masoum, M. A. S., and Abu-Siada, A. 2011. "Smart Load Management of Plug-In Electric Vehicles in Distribution and Residential Networks with Charging Stations for Peak Shaving and Loss Minimisation Considering Voltage Regulation." IET Gen., Transm. \& Distrib. 5 (8): 877-88.

[2] Putrus, G. A., Suwanapingkarl, P., Johnston, D., Bentley, E. C., and Narayana, M. 2009. "Impact of Electric Vehicles on Power Distribution Networks." In Proceedings of the 2009 IEEE Vehicle Power and Propulsion Conference, 827-31.

[3] Acha, S., Green, T. C., and Shah, N. 2010. "Effects of Optimised Plug-In Hybrid Vehicle Charging Strategies on Electric Distribution Network Losses." IEEE PES T \& D 2010, 1-6.

[4] Hoog, J. D., Alpcan, T., Brazil, M., Thomas, D. A., and Mareels, I. 2014. "Optimal Charging of Electric Vehicles Taking Distribution Network Constraints into Account." IEEE Transactions on Power Systems 30 (1): 365-75.

[5] Shao, S., Pipattanasomporn, M., and Rahman, S. 2009. "Challenges of PHEV Penetration to the Residential Distribution Network." Power \& Energy Society General Meeting 1-8.

[6] LUO, X., and CHAN, K. W. 2014. "Real-Time Scheduling of Electric Vehicles Charging in
Low-Voltage Residential Distribution Systems to Minimise Power Losses and Improve Voltage Profile." IET Generation, Transmission \& Distribution 8 (3): 516-29.

[7] Callaway, D. S., and Hiskens, I. A. 2011. "Achieving Controllability of Electric Loads." Proceedings of the IEEE 99 (1): 184-99.

[8] Karfopoulos, E. L., and Hatziargyriou, N. D. 2013. "A Multi-agent System for Controlled Charging of a Large Population of Electric Vehicles." IEEE Trans. Power Syst. 28 (2): 1196-204.

[9] Schuller, A., Dietz, B., Flath, C. M., and Weinhardt, C. 2014. "Charging Strategies for Battery Electric Vehicles: Economic Benchmark and V2G Potential." IEEE Transactions on Power Systems 29 (5): 2014-22.

[10] Hutson, C., Venayagamoorthy, G. K., and Corzine, K. A. 2008. "Intelligent Scheduling of Hybrid and Electric Vehicle Storage Capacity in a Parking Lot for Profit Maximization in Grid Power Transactions." In Proceeding of the Energy 2030 Conference, 2008. ENERGY 2008. IEEE, 1-8.

[11] Department for Transport. 2014. "National Travel Survey 2014."

https:/www.gov.uk/government/publications/statistics/na tional-travel-survey-2014.

[12] National Grid. "Historical Demand Data." http://www2.nationalgrid.com/UK/Industry-information/ Electricity-transmission-operational-data/Data-explorer/.

[13] House of Parliament. "Electric Vehicle." http://researchbriefings.parliament.uk/ResearchBriefing/S ummary/POST-PN-365.

[14] "Electric Vehicle Conductive Charging System-Part 1: General Requirements." IEC 61851-1. 2001.

[15] Bruno, S., and Jurgen, G. 2010. "Lithium Batteries: Status, Prospects and Future.” J. Power Sources 195 (9): 2419-30.

[16] Nocedal, J., ed. 2006. Numerical Optimisation. Berlin: Springer.

[17] Wayne, L. W., ed. 1995. Introduction to Mathematical Programming: Applications and Algorithms. ISBN 0534359647.

[18] YAO, W., ZHAO, J., WEN, F., XUE, Y., and Ledwich, G. 2013. "A Hierarchical Decomposition Approach for Coordinated Dispatch of Plug-In Electric Vehicles." IEEE Trans. Power Syst. 28 (3): 2768-78. 